\title{
Harmonising Food Frequency Questionnaire (FFQ) for South East Asia for Accurate Dietary Data Interpretation
}

\author{
Hamid Jan B. Jan Mohamed ${ }^{1}$ \\ 1. Nutrition and Dietetics Programme, School of Health Sciences, Universiti Sains Malaysia, \\ 16150, Kubang Kerian, Kelantan, Malaysia
}

Received 21 December 2019,

Link to DOI:

10.25220/WNJ.V03.i2.0001

Journal Website:

www.worldnutrijournal.org

South East Asia (SEA) is an ethnically diverse region but still share some similarities with regards to food intake ${ }^{1}$. Each country within SEA can be considered as food heaven with its diversity of dietary choices and creativity in food preparations. Within SEA, each individual country is also unique due to its culture, tradition and food choice. Additionally, cross country immigration for economic purpose also demand healthcare providers of host country some additional tasks for evidencebased dietary advice as their training were mostly focused at local foods. For researchers on regional dietary intake huge challenge appears when comparison between countries are made with regards to dietary intake. It raises two pertinent questions. Is it correct to compare food date collected using unstandardized dietary intake tool? Is it possible to harmonise the dietary data and produce a FFQ as a standard tool?

Generally, food frequency questionnaires (FFQs) are designed to assess habitual dietary intake by asking about the frequency and portion intake

\footnotetext{
Corresponding author:

Hamid Jan B. Jan Mohamed

Nutrition and Dietetics Program, School of Health

Sciences, Universiti Sains Malaysia, Malaysia

Email: hamidjan@hotmail.com
}

with which food items of specific food groups are consumed over a set period. ${ }^{2}$ The advantage and disadvantages of FFQ compared to other dietary tools are well documented. ${ }^{3}$ Nevertheless, FFQ is well accepted in some large studies as the appropriate tool for dietary data collection. ${ }^{4}$ However, these large studies are isolated to specific countries and any dietary intake findings is refrained to the specific country only. Recently, there are initiatives to merge and harmonise multiple FFQ result into a single data set. The biggest initiative so far is led by research team at the Tufts University with the Global Dietary Database Consortium (www.globaldietarydatabase.org)..$^{5} \quad$ Another initiative is the NutriGen Alliance which combined FFQ data from 4 ethnically diverse birth cohorts within Canada ${ }^{4}$. The latter group reported strong association of "plant based" diet with the modified Alternative Healthy Eating Index. These are excellent initiative and important findings as the results are generated from huge dietary datasets with appropriate statistical techniques. However, one limitation of these initiative is the dietary data results are obtained through different set of FFQ's which were designed according to each researcher's objective. Nevertheless, such initiatives should be encouraged but other possible options should also be explored. The idea of designing FFQ starting from 
early stage by considering local dietary elements of the countries should be tested. With the advancement for internet technology, researchers from SEA could communicate actively in designing a standard FFQ which could be tasted among population in individual countries. Perhaps, this approach may produce more accurate data with fewer variations and could be applied in multiple countries any may benefit populations in this region.

\section{Conflict of Interest}

Authors declared no conflict of interest regarding this study.

\section{Open Access}

This article is distributed under the terms of the Creative Commons Attribution 4.0 International Licence

(http://creativecommons.org/licenses/by/4.0/), which permits unrestricted use, distribution, and reproduction in any medium, provided you give appropriate credit to the original author(s) and the source, provide a link to the Creative Commons license, and indicate if changes were made.

\section{References}

1. Van Esterik P. Food culture in southeast Asia. Greenwood Publishing Group; 2008.

2. Wakai K. A review of food frequency questionnaires developed and validated in Japan. Journal of epidemiology 2009 Jan;19(1):1-1. [Google Scholar]

3. Gibson RS. Principles of nutritional assessment. Oxford university press, USA; 2005.

4. Investigators NA, Souza, R.J. de , Zulyniak MA, Desai D, Shaikh MR, Campbell NC, et al. Harmonization of food-frequency questionnaires and dietary pattern analysis in 4 ethnically diverse birth cohorts. The Journal of nutrition 2016 Nov;146(11):2343-50. [Google Scholar]

5. Micha R, Coates J, Leclercq C, Charrondiere UR, Mozaffarian D. Global dietary surveillance: data gaps and challenges. Food and nutrition bulletin 2018;39(2):175-205. [Google Scholar] 